\title{
Reflexões sobre espaço e comunicação: a transformação da experiência em cotidianos urbanos
}

\author{
Reflections on space and communication: \\ the transformation of experience in urban daily
}

\author{
Renata Rezende | Universidade Federal Fluminense \\ Professora do Programa de Pós-Graduação em Mídia e Cotidiano (PPGMC-UFF). \\ Pós-Doutorado em Comunicação e Cultura (UFRJ); Doutora em Comunicação e \\ Mestre em Comunicação e Imagem (ambos pela UFF) \\ E-mail: renatarezender@yahoo.com.br \\ Laura Bedran | Universidade Federal Fluminense \\ Professora do Programa de Pós-Graduação em Mídia e Cotidiano e do \\ Departamento de Comunicação Social da UFF. Doutora em Comunicação. \\ E-mail: laura.bedran@yahoo.com.br
}

\begin{abstract}
Resumo
Por meio de ensaio, o texto objetiva problematizar as transformaçóes do espaço, levando em conta as diferentes formas e relaçóes informacionais que afetam as interaçôes humanas e temporalidades que as atravessam e lhes dão sentido, na articulação da experiência cotidiana. Para tanto, se interroga a materialidade construída no tempo/espaço, que transforma o cotidiano dos sujeitos imersos em territórios mobilizados pela mídia e conectados por tecnologias de comunicação. Destaca-se a transformação da cidade a partir dos fluxos de informação, a comunicação em rede, as mídias dos espaços urbanos e as relaçóes comunicativas geográficas e/ou culturais, particularmente da sociedade ocidental do século XIX ao século XXI.

Palavras-Chave: Tecnologias de Comunicação; Espaço; Cotidiano
\end{abstract}

\begin{abstract}
The paper aims to discuss the transformations of space, taking into account the different forms and informational relationships that affect human interactions and frames that go through and give them direction, the articulation of everyday experience. It questions the materiality built in the time / space that transforms the daily lives of individuals immersed in territories mobilized by the media and connected by communication technologies. The transformation of the city from the flow of information, network communication, the media of urban spaces and geographical communicative relationships and / or cultural, especially in Western society of the nineteenth century to the twenty-first century
\end{abstract}

Keywords: Communication technologies; Space; Everyday life 
Rodeados não somente por uma tecnologia diversificada que tem, entre tantas funções, como principal - a conexão -, talvez fosse mais fácil perguntarmos: o que não é comunicação? É fato que estamos inseridos em um mundo onde tudo quer comunicar. A comunicação se estende muito além dos suportes especialmente projetados para este fim: sinais, gestos, imagens, corpos, objetos, design de interiores, arquitetura, urbanismo... em várias escalas, a comunicação se expande.

Quando Roland Barthes (1979, p.4) apontou a possível similaridade entre objetos, tais como vestidos, automóveis, anúncios publicitários ou mesmo gestos, entre outros, afirmando que "pelo menos isto: são todos signos" se evidenciam as várias possibilidades de comunicação nesta complexa "cozinha dos sentidos” do contemporâneo.

A noção contemporânea de comunicação é tão vasta que exige alargamento também da noção de seus territórios e espacialidades - domínios que expandem, em muito, a concepção do clássico modelo Emissão - Recepção. Os múltiplos sentidos que, desde antes, vem sendo instigados pelas várias possibilidades deflagradas nos ambientes cotidianos urbanos, sem dúvida, com "a proliferação das tecnologias e a profissionalização das práticas acrescentaram novas vozes a essa polifonia, num fim de século que faz da comunicação figura emblemática da sociedade do Terceiro Milênio" (MATTELLARD, 2004, p.9).

É possível pensarmos a comunicação como um ato cotidiano mediado pela experiência no espaço contemporâneo. Além, claro, de pensarmos no quanto ela circula, interfere, une e ao mesmo tempo segrega, distingue e determina. Para compreendermos essa multiplicidade de ações e sentidos que permeiam a comunicação contemporânea, é pertinente olharmos um pouco para trás, quando a comunicaçáo tomada como um processo de interação entre emissor e receptor parecia menos complexa.

A divulgação de um pensamento como propagação ideológica ou cultural está marcada na história remota do mundo e das civilizaçôes. Inegável o papel desempenhado pelas doutrinas religiosas com grande poder de comunicação emanado das imagens idealizadas do cristianismo sobre uma população, em sua grande maioria, de cultura oral. Outro exemplo desse processo de interação informacional, já há muito vivido nesse velho mundo, são as viagens marítimas transnacionais. Movidas pela expansão de mercados e territórios, essas viagens promoveram a globalização de costumes - com destaque são retratadas as feiras populares na Veneza renascentista, repletas de mercadorias de diferentes partes do mundo que encantavam olhares curiosos; e o processo colonizador que, de forma impiedosa, escravizou diferentes, impôs costumes e devastou culturas, mas também promoveu interaçóes.

Com o surgimento da imprensa, no século XV, o processo de comunicação impóe-se mediado por um veículo, onde, principalmente, a reprodução em larga escala lhe dá inegável possibilidade de expansão. Como categoria de instituiçóes de mediação, os livros, os jornais e os folhetos promovem novas formas simbólicas de contato intelectual que, além da profissionalização da divulgação de ideias, promovem "a progressiva laicizaçáo do pensamento filosófico, político e social” (FERRIN, 2002, p.16). 
Além da divulgação de ideias, saberes e comportamentos e, por conseguinte, a progressiva expansão intelectual, o hábito da leitura promoveu uma ação de grande poder na sensibilidade humana ao formatar o modo de olhar. A esse respeito, McLuhan (1964) desenvolve a ideia dos meios como extensão do homem, como órgáos amplificados, onde sentidos e funçôes humanas estariam diretamente afetados: "toda extensão é a amplificação de um órgão, de um sentido ou de uma função que inspira ao sistema nervoso central (MCLUHAN,1964, p.197).

Sua análise sobre o livro impresso não se detém nas possibilidades ampliadas de pensamentos e ensinamentos em massa, mas revela o quanto a palavra escrita formatada ao modo tipográfico determina uma estrutura da escrita que afeta a sensibilidade. Dessa forma, o livro como extensão do humano passa a exigir uma sensibilidade que se organiza para a leitura (MCLUHAN,1964). A escrita impressa através do livro, ao modo como foi concebido pela tipografia, com a precisa linearidade, uniformidade e continuidade na leitura, apresentou-se com uma estrutura visual que deu início a uma espacialização da comunicação que, dessa forma, compreendeu uma intensificação para o ponto de vista particular: "psicologicamente o livro impresso, como extensão da faculdade visual, intensificou a perspectiva e o ponto de fuga fixo" (MCLUHAN,1964, p.197). Este campo determinado entre a leitura e o leitor passou a ser um campo de fluxos, no qual a subjetividade mistura-se ao campo informacional repercutindo em repertórios múltiplos pela autonomia do receptor. Fechado em seu campo visual, o leitor e o livro dialogam intensamente, a possibilidade imaginária contida nesta relação é grande.

\section{O espaço moderno e a transformação do cotidiano}

Instalada a escrita impressa como primeiro modelo moderno de comunicação em massa, sua expansão acompanhou os movimentos do mundo com inovaçôes tecnológicas. Progressivamente, aldeias foram sendo transformadas em cidades que difundiram a urbanização muito além dos sistemas viários e habitacionais, gerando também uma cultura urbana de convivência, consumo e lazer. O planejamento que as cidades modernas adquiriam no século XIX, um modelo urbano reproduzido em várias cidades do mundo, caracterizou-se por uma organização voltada para o funcionamento racional do espaço, com a cidade fracionada em regióes de trabalho, lazer e moradia, conectadas em intensos fluxos. Apesar dessa racionalidade aparente imposta pelo espaço urbano moderno, a experiência cotidiana imputou aos indivíduos citadinos uma nova sensibilidade: em um jogo de congruências múltiplas a tecnologia, o lazer e o consumo misturaram-se à racionalidade e alteraram significativamente as relaçóes entre o espaço e o tempo dentro do cotidiano das cidades.

A cidade descrita, como um novo espaço para a experiência humana em meio às crescentes modernizaçóes, encontra eco na análise de Walter Benjamin (1980): a experiência da cidade moderna como uma experiência sensorial. Ao contextualizar as inovaçóes técnicas do século XIX e as decorrentes mudanças, emerge com grande força esta nova cidade, que passa a explorar o corpo humano em seus vários sentidos. $\mathrm{O}$ autor propóe que as novas invençóes que surgiram em vários campos, como fósforos, telefone, fotografia, carro, entre 
outras, foram invençóes que substituíram com um simples gesto, açôes antes muito mais complexas; e todas elas seguidas de um choc. A experiência do choc tem como significado a reaçáo aos estímulos através da consciência. Recorrendo a Freud, Benjamin explica que a experiência como um trauma ocorre quando a apreensão se dá sem as devidas defesas do organismo, as quais são proporcionadas pela consciência. $\mathrm{O} c h o c$, ao ser aparado pela consciência, daria ao acontecimento o sentido de vivência (BENJAMIN et. al., 1980), neutralizando o suposto efeito traumático. Ora, se assim se processa o binômio choque e experiência, o autor sugere que as sucessivas experiências de choques provocadas no cotidiano urbano têm o objetivo de neutralizar o aspecto traumático da vida urbana e promover a adaptação gradual do homem a esse novo e "estranho" modo de vida.

O autor também pretende mostrar que a aplicabilidade da técnica em larga escala sobre as diferentes categorias da vida moderna, desde as mais práticas, como a exemplificada pelos fósforos, às mais subjetivas, como a apreciação da arte, propicia no indivíduo constantes experiências sensoriais de estímulos sucessivos. Dessa forma, a vida passa a ser mediada por estas experiências sensoriais cotidianas, que promovem uma espécie de fruição e prazer em sua apreciação. Abre-se, nesse sentido, uma importante discussão que aponta as questôes relacionadas à cultura de massa, que no século XX encontra seu desenvolvimento através dos meios de comunicação e da indústria cultural que a alicerça. A afirmativa fica mais evidente quando, principalmente, a fotografia, o cinema e a arte tornam-se objetos de análise do autor, relacionados à reprodução técnica da obra que se aplica às três modalidades:

As técnicas de reprodução aplicadas à obra de arte modificam a atitude da massa com relação à arte. Muito retrógrada face a um Picasso, essa massa torna-se bastante progressista diante de um Chaplin, por exemplo. O caráter de um comportamento progressista cinge-se a que o prazer do espectador e a correspondente experiência vivida ligam-se, de maneira direta e intima, à atitude do aficionado. Essa ligação tem uma determinada importância social. Na medida em que diminui a significação social de uma arte, assiste-se no público a um divórcio crescente entre $o$ espirito crítico e o sentimento de fruição (BENJAMIN et al., 1980, p. 21).

Apesar do reconhecimento da cidade como uma nova experiência, com significados subjetivos para o homem urbano, Benjamin (1980), ao relacionar a ausência de crítica ao prazer da fruição, expõe também a imbricação entre os objetos da cultura de massa e o conceito de alienação, afinados ao discurso crítico de Adorno (1988) e dos pensadores da Escola de Frankfurt.

Se nos jornais, o desenho já ilustra com desenvoltura o cotidiano, paralelamente, uma outra técnica, a fotografia, se desenvolve para criar uma linguagem própria. Assim, sucessivamente, as manifestaçóes artísticas vão sendo afetadas pelas técnicas de reprodução: a pintura se reproduzem cartazes, a orquestra se reproduzem música nos gramofones, o teatro em filmes, e dessa maneira, com tamanha desenvoltura, que alteram o conceito histórico tradicional de arte: são obras que se impóem em sua apresentação a um grande público e se validam na reprodução como formas originais de arte (BENJAMIN et al., 1980). 
A expansão da publicidade, em razóes de um modelo econômico, da demanda de um mercado e da formação de um público consumidor nas cidades crescentes, acentua a experiência cotidiana envolvida como uma atividade prazerosa mediada pela comunicação. Ir às compras, uma ação antes comum, corriqueira e necessária, ganha nova roupagem nas cidades modernas com vitrines sedutoras e lojas de departamentos, nas quais os produtos etiquetados com preços passam a refletir o novo modelo de comércio, onde náo mais se impunha a negociação, deixando ao cliente a liberdade de circular entre as mercadorias e o deleite de, talvez, apenas apreciar (RAPPAPORT, 2004). Paralelo a isso, uma estratégia de excitação atua nos anúncios de promoções, na decoração das vitrines e na diversidade de produtos.

Os cartazes publicitários passam a compor o ambiente urbano associando o desenvolvimento da indústria gráfica com a criatividade de artistas que traduziam as bases do design aplicado à comunicação gráfica de massa. $\mathrm{O}$ cartaz de rua irá, pioneiramente, mapear características estritamente urbanas ao exigir legibilidade textual, impacto de cores e síntese de formas, além da repetição - colados lado a lado - como essenciais para a leitura em meio ao ambiente das cidades.

Os estímulos que estáo por toda a parte nas cidades modernas promovem a potencialização da imagem que pode ser percebida nas mudanças alavancadas pelos processos de industrialização e urbanização, que passaram a fornecer ao indivíduo das cidades uma nova experiência visual. Crary (2004) classifica essa experiência como uma modernização do olhar que já se organizava muito antes da invenção do cinema, no final do século XIX, transformando o padrão clássico de observação. Para o autor, as mudanças percebidas nos campos científicos, como a que relaciona a experiência visual atrelada à experiência sensorial, acarretaram novas condições de aplicabilidade de técnicas de manipulação e estímulo:

Uma vez determinado o fato de que a verdade empirica da visão situavase no corpo, os sentidos - e a visáo em particular - puderam ser anexados e controlados por técnicas externas de manipulação e estimulação. Essa foi a conquista histórica da ciência da psicofísica nos meados do século XIXsobretudo o trabalho do cientista-filósofo Gustav Fechner - que tornou a sensação mensurável e firmou a percepção humana no dominio do quantificável $e$ do abstrato. A visão, assim, tornou-se compativel com muitos outros processos da modernização (CRARY, 2004, p. 68).

Sobre as modernizaçôes impostas ao olhar nas paisagens das cidades, Nelson Brissac Peixoto (2003) também faz referências à formação de um novo observador, o qual chama de "observador ambulante". Não mais contemplativo de um objeto único, este observador que circula nos grandes centros, é formado pela convergência de espaços, tecnologias e imagens; capaz de acessar múltiplas e sobrepostas visões de um mundo em constante circulação. "A pluralidade de vistas foi condição para a formação de um observador competente para assumir as vastas quantidades de imagens e informaçóes que começavam a ser postas em circulação no século XIX” (PEIXOTO, 2003, p. 97-98). 
Podemos dizer que o modelo de urbanização que se desenvolveu no século XIX favoreceu a construção de um espaço mediado pela experiência. As condiçôes instauradas pela urbanizaçáo sobre as diversas modalidades da vida cotidiana tomaram, em conjunto, a cidade como um suporte a ser experienciado. Midiaticamente, a cidade moderna expandiu territórios informacionais. Desde a imprensa de tipos móveis, no século XV, diversas condiçóes materiais e tecnológicas foram determinando modos de perceber a comunicação sobre elas expressas, assim como o mundo.

Na passagem dos séculos XX para o XXI, com o hibridismo dos meios de comunicação, a mídia passou a implicar uma nova qualificação da vida, ou como afirma Muniz Sodré (2002), um bios virtual, no qual o usuário pode entrar e mover-se em ambientes digitais, graças à interface gráfica, trocando a representação clássica pela "vivência apresentativa", onde mais uma vez os conceitos de tempo e espaço são alterados, na medida em que a forma condicionante da experiência é ampliada pelaaceleração epela circulação das coisas no mundo. A partir da influência do novo sistema de multimeios, atravessado por interesses sociais, políticos e mercadológicos, emerge uma outra forma de viver o espaço nas cidades.

\section{O ciberespaço e a experiência contemporânea}

No estágio da cibercultura, os territórios e o cotidiano urbano se reconfiguram a partir da emergência de novos formatos comunicacionais, que passam a incluir as tecnologias sem fio, o espaço conectado e virtual e as redes e relaçôes cada vez mais digitalizadas, "as cidades se desenvolvem como sociedades em rede” (LÉVY e LEMOS, 2010, p.121-122).

A vida cotidiana atravessa e é atravessada pelo espaço cibernético, o qual inaugurou novos fluxos, afetos e alegorias, ou como afirma Jaguaribe (2007, p.16), a realidade tornou-se fabricada: " uma das postulaçôes da modernidade tardia é a percepção de que os imaginários culturais são parte da realidade e que nosso acesso ao real e a realidade somente se processa por meio de representaçóes, narrativas e imagens". É nesse sentido que tomamos o conceito de cotidiano a partir de Agnes Heller (2008), que o considera como um processo ininterrupto de invençôes humanas na tessitura da história. Para a autora, é importante analisar as açóes do cotidiano porque é por meio dele que se assimila o outro e o mundo e, nesse contexto, também (e talvez principalmente) o espaço.

$\mathrm{Na}$ contemporaneidade, a representação do espaço passou a incorporar novas formas (o virtual, o espaço simulativo ou telerreal da hipermídia) expandindo ainda mais a dimensão tecnocultural, onde se constituem e se movimentam os sujeitos sociais. Uma nova modalidade de representação se instaura, supondo outro espaço-tempo social (imaterialmente ancorado na velocidade do fluxo eletrônico e digital), e, por certo, um novo regime de visibilidade pública, na qual a lógica espetacular se amplia. Novas tecnologias de som e de imagem passam a constituir o campo do audiovisual, proporcionando ao receptor acolher o mundo em seu fluxo, ou seja, a partir da simulaçáo de um tempo "vivo" ou "presente", no qual a materialidade incorpora outros significados com as ferramentas da multimídia. 
Segundo Castells (1999, p.355), uma "cultura da virtualidade real”, em que a própria realidade (a experiência simbólica e material dos sujeitos) “é inteiramente captada, totalmente imersa em uma composição de imagens virtuais no mundo do faz-de-conta, no qual as aparências não apenas se encontram na tela comunicadora da experiência, mas se transformam na experiência" (CASTELLS, 1999, p. 395).

Esse sistema de comunicação modifica as dimensôes fundamentais da vida: localidades reais e imaginadas são despojadas de seu sentido histórico, geográfico e cultural, reintegrando-se em redes fragmentárias de texto e imagens, em uma esfera cada vez mais fluida. Passado, presente e futuro se confundem para interagir no mesmo conteúdo: a imaterialidade e a mobilidade se tornaram palavras de ordem no cenário do século XXI.

Compreender as particularidades desse fenômeno técnico, bem como seu papel no mundo contemporâneo não é simples. Devido à penetrabilidade em todas as esferas da atividade humana, a chamada "revoluçáo tecnológica da informação" nos obriga a mudar o olhar e a buscar ferramentas para entender esse novo suporte, inserido em um paradigma sociocultural muitas vezes desacreditado de grandes ideologias, e em contextos políticos fracassados.

As tecnologias digitais surgiram como a infraestrutura do ciberespaço (JOHNSON, 2001), enquanto local de organização de um novo mercado da informação e do conhecimento, mas também de comunicação e de sociabilidades. Nesse cenário, tais tecnologias se desenvolveram, possibilitando a veiculação de mensagens em um mesmo suporte - o computador - e dessa tecnologia decorreu uma nova mídia - a Internet - que passou a implicar outra qualificação da vida, ou como supracitado, a partir de Sodré (2002), um bios virtual, que consiste em outra dimensão da realidade, com outras formas de perceber, pensar e formular a "materialidade", particularmente em sua referência física.

Apesar de autores como Pierre Lévy (1999) e Jean Baudrillard (2002) afirmarem que o virtual provocou a anulação do espaço pelo tempo, gerando novos canais de distribuição de bens e de indivíduos, que se tornaram imagens e passaram a formatar seus corpos dentro de um ambiente artificial, acreditamos que o espaço não foi anulado, mas multiplicado em novas possibilidades geradas pela própria tecnologia. Compreendemos que há uma complexificaçáo dos espaços possíveis de serem habitados (REZENDE, 2009). Nós, bifurcaçóes, pontos de referência, janelas imaginárias abriram outras dimensóes virtuais, constituindo novas possibilidades que determinaram outras formas de se conceituar o espaço, lembrando, inclusive, o próprio corpo enquanto espaço material e virtual, o qual se relaciona as dimensôes fundamentais da mobilidade, que segundo Lemos são (2011, p.16): a física, a informacional-virtual e a do pensamento.

Richard Sennett (1997), em uma reconstituição da história do corpo, lembra-nos como "o homem moderno é, acima de tudo, um ser humano móvel”. O sociólogo desenvolve seu pensamento a partir da revolução científica de William Harvey ${ }^{1}$, o qual transformou a compreensão do corpo, relacionando-o ao advento do capitalismo moderno, que resultou em uma visáo de liberdade associada ao fato de mover-se (REZENDE, 2005). Sennett afirma que no século 
$\mathrm{XX}$ as pessoas passaram a se deslocar rapidamente, especialmente em função de um "movimento total" condensado na tecnologia do automóvel. A partir da experiência corporal, o autor buscou uma "nova história da cidade". Para Sennett, "o individualismo moderno sedimenta o silêncio dos cidadãos na cidade. (...) os lugares são para se passar à vista, mais do que cenários destinados a conversaçóes (...) nossa ágora só existe na aparência (...) a cidade acabou por realizar o ideal iluminista do corpo em movimento" (SENNETT, 1997, p. 214).

No século XXI, "não podemos dissociar comunicação, mobilidade, espaço e lugar” (LEMOS, 2011, p.17), na medida em que a comunicação desloca a informaçáo de um espaço a outro, criando e reconstituindo sentidos, significados e subjetividades. $\mathrm{O}$ autor explica as dimensóes da mobilidade - a física (corpos e objetos), a do pensamento (como desterritorialização por excelencia, a partir de Deleuze e Guattari) e a informacional-virtual -, enquanto constituiçôes fundamentais para se compreender a cultura contemporânea, e ressalta que a mobilidade também evidencia sistemas de poder, devendo ser interpretada, inclusive, como performance (LEMOS, 2011, p.16-17). Segundo Lemos, existe, hoje, uma correlação entre as mobilidades informacional e física, no que diz respeito ao acesso às tecnologias e objetos, pois, para o autor, "quanto maior for a potência de mobilidade informacional-virtual, maiores serão a mobilidade física" ou "os que podem se movimentar mais facilmente pelo ciberespaço são também os que têm maior autonomia para o deslocamento físico e vice-versa" (LEMOS, 2011, p.17-18).

Massey (apud Lemos, 2011, p.18), lembra que as disparidades no que tange às mobilidades se relacionam às "diferentes hierarquias e geografias de poderes". A narrativa do espaço e a cultura da mobilidade se transformam segundo as épocas, os contextos e a história de cada lugar. De acordo com Lemos (2011), é preciso levar em conta as noçôes de extensibilidade e de acessibilidade, as quais, segundo o autor, são complementares, na medida que uma refere-se à capacidade do sujeito ou do grupo de superar as dificuldades de movimento e a outra refere-se à potência para chegar ao ponto desejado. Em conjunto a essas dimensóes, entram em cena a velocidade e a aceleração, vetores valorizados na sociedade da informação, na qual "a mobilidade se transforma em imperativo de conquista” (LEMOS, 2011, p.19) porque participa do tipo de formato histórico que amplia o espaço virtual, com as redes telemáticas e as conexóes cada vez mais móveis e sem fio.

Nesse cenário, a produção de imagens deixa de ser um efeito de duplicação e representação, para tornar-se processo de construção e simulação, processo que resulta em uma mediaçáo tecnológica exacerbada, na medida em que os sujeitos são solicitados a viverem no interior de ambientes tecnocomunicacionais, onde a interatividade e a conectividade são permanentes e a mídia torna-se espaço autônomo e privilegiado por atuar diretamente na construçáo do real. Fatos e coisas passam a ser reapresentados a partir de um tempo vivo e a simulação torna-se uma representação apresentativa (SODRÉ, 2002), na qual a conjuntura temporal, marcada pela aceleração, configura outros sentidos de lugar, novas territorializaçóes. 
Segundo Sodré (2002), desde o pós-guerra, a revolução informacional vem transformando a "própria estruturação das percepçóes", ao integrarem os mecanismos clássicos da representação aos novos dispositivos virtuais. Isso porque o conceito de midiatização decorre da articulação híbrida de múltiplas instituiçôes com diversas organizaçôes de mídia, com atividades tecnológicas e mercadológicas. Diante de uma sociedade assim constituída, viveríamos agora, em uma era na qual a materialidade física se transforma em imagem, se oferecendo como "ilusão da forma", a partir da qual se pode experimentar estruturas, corpos e cidades no fluxo da virtualidade do ciberespaço.

Num primeiro momento, caracterizado como espaço complexo, o ciberespaço se configura como território presente em vários lugares e, ao mesmo tempo, em lugar algum. Ao desconectar a tomada do equipamento que o abriga (determinado computador), ele desaparece, mas continua existindo alhures. Em Uma História do Espaço: de Dante à Internet, Wertheim propóe um percurso sobre a constituição da espacialidade, considerando que fatores presentes na cultura ocidental resultaram em uma crença de que o ciberespaço, hoje, tornou-se o foco de sonhos essencialmente religiosos. A autora tenta compreender porque esse espaço digital é visto como uma tentativa de se construir um substituto tecnológico para o lugar cristão do Paraíso, onde "junto com a libertação da dor, virá também a libertação máxima”, na medida em que o deslocamento se realiza sem o corpo físico (WERTHEIM,2001, p.13).

O termo ciberespaço, inventado pelo escritor de ficção científica William Gibson, em 1984, descreve um conjunto de redes de computadores por meio dos quais todas as informações circulavam. Desta forma, é possível compreender o ciberespaço como um ambiente simulado (realidade virtual) e como o conjunto de redes de computadores, interligadas por meio da Internet. O ciberespaço é uma entidade real (LEMOS, 2002), pois faz parte de uma cultura planetária crescente. Em vez de um espaço fechado, é um local transnacional onde o corpo é suspenso pela abolição da noção do espaço convencional e pelos usuários que entram em jogo em diversos meios de sociabilidade.

Se a tendência da física foi gradualmente abolir a matéria em função do espaço (corpo como matéria), no ciberespaço a questão do corpo (sua presença nesse espaço de informação) torna-se fundamental. Sendo um local de informação, tudo se torna fluido e mutável. O conceito de rede aparece como um conglomerado de nós e de bifurcaçóes e, de cada nó é possível enxergar outro nó e nunca sua borda. Isso faz com que tenhamos a impressão de estarmos imersos em um espaço infinito (não que ele não tenha fim, mas porque não conseguimos ver o fim).

O aparecimento cada vez maior de ferramentas múltiplas possibilitou a criação de espaços específicos de comunicação dentro do ciberespaço, unindo sujeitos com interesses comuns em comunidades virtuais e redes de sociabilidade, como as redes sociais digitais. Para Janet Murray (1999), o computador passou a ser visto como espaço a partir do momento em que, através da interatividade com o programa, o usuário sentia que era possível modificar o espaço 
“do outro lado da tela". Tornou-se possível perceber a presença do outro no ambiente virtual, permitindo, inclusive, a criação de espaços como mundos, ou seja, como lugares habitados e modificados por seus habitantes.

O ciberespaço pode ser visualizado a partir da metáfora da noosfera² ${ }^{2}$ uma camada da consciência humana digitalizada, na medida em que é uma espécie de pele abstrata, na qual circulam informaçóes e pessoas, como espectros digitais. Toda a rede telemática é utilizada para o transporte de conteúdos diversos como trocas de arquivos, fotos, vídeos, músicas, entre outros, com velocidade cada vez mais ampliada. No contexto da comunicaçáo planetária e multimodal, a rede agrega pessoas, independentemente da localidade geográfica, inibindo, se desejado, referências materiais (físicas) e abstratas (religião, política e econômica).

\section{Considerações finais}

A partir dessa percepção, o ciberespaço não seria mais um espaço de simulação da vida, mas a própria vida, tornando-se novo campo de possibilidades. Essa concepção de um espaço desmaterializado do corpo faz parte do antigo sonho de criação de um mundo paralelo, "pós-humano". É a partir dessa concepção que problematizamos a experiência da vida cotidiana nas grandes cidades, na medida em que se instaura um paradoxo: o espaço midiatizado das redes digitais se multiplica em informação, proporção e velocidade, enquanto o espaço físico torna-se cada vez mais obstruído pelo excesso de materialidade (construçóes, sistemas e pessoas).

O sistema capitalista inaugura megalópoles caóticas e asfixiantes, distribuindo poluição visual: vive-se um cotidiano midiatizado. Nessa realidade, "as instituiçôes, as práticas sociais e culturais articulam-se diretamente com os meios de comunicação, de tal maneira que a mídia se torna progressivamente o lugar por excelência da produção social de sentido, modificando a ontologia tradicional dos fatos sociais", configurando-se o que Sodré (2002, p. 27) denomina como "sociedade midiatizada". Para Beatriz Jaguaribe, "há, nos meios de comunicação, uma produção de realidades exacerbada pelo sensacionalismo, pela propulsão do choque, pela necessidade imperiosa de produzir novidades, pela vertiginosa velocidade de informaçóes fragmentárias que não compóem um retrato total do social-global" (JAGUARIBE, 2007, p.17).

O presente cotidiano é cada vez mais midiatizado, articulado por redes de conteúdos informacionais (notícias, entretenimento, publicidade, jogos, entre outros) produzindo diferentes formas e interaçôes em múltiplas referências simbólicas. Nesse contexto, o efêmero atua, não como "criação exclusiva da velocidade, mas de outra vertigem, trazida com o império da imagem e a forma como ela é engendrada" (SANTOS, 2013, p.28). A urgência e a velocidade imprimem o ritmo do cotidiano, ou como acreditam Lipovetsky e Serroy (2015, p.416), o homem apressado que outrora representou a euforia da descoberta da velocidade como parte do romantismo da Modernidade, na qual a aceleração é contínua, agora não traduz mais do que a imagem de um indivíduo na "busca impossível de si”. 
No espaço contemporâneo, a complexidade urbana se intensifica, segundo a transformação do próprio capitalismo. Para Lipovetsky e Serroy (2015, p.315), “a estetização de todos os elementos que compóem e organizam a vida cotidiana” está relacionada ao estágio das maneiras de se consumir que "coincide com a generalização das estratégias de sedução estética, com o desenvolvimento da mise-em-scène da cidade e dos entornos comerciais". Trata-se, segundo os autores, da "cidade franqueada", que vive sob a égide do consumo e é caracterizada pela saturação de espaços comerciais e pela influência mercadológica. Os espaços que se constituem são concebidos como mídia, e tudo deve comunicar em um ritmo acelerado.

Diante desse cenário, nossa maior contribuição é a de pensar o contexto das práticas comunicacionais cotidianas, atreladas ao desenvolvimento de novos regimes de processamento de informação que configuram sujeitos, suas ações e experiências. Portanto, reforçar a importância da tecnologia e da mídia nos estudos sobre a sociedade contemporânea e refletir acerca de como os espaços são tomados no cotidiano, a partir das práticas atravessadas pelos meios de comunicação. Para Heller (2008), a circunstância histórica, onde o homem constitui suas finalidades, "é a unidade de forças produtivas, estrutura social e formas de pensamento, ou seja, um complexo que contém inúmeras posiçóes teleológicas". De acordo com a autora (2008, p. 32-33), "a vida cotidiana é a vida de todo homem", portanto, o lugar, o espaço, a cidade também é o cotidiano, ou como lembra Santos (1999, p.251), "cada lugar é, à sua maneira, o mundo" ou o "intermédio entre o mundo e o indivíduo".

Estamos em meio a este emaranhado de técnicas e dependências no qual vivemos, inclusive em formatos simultâneos, onde é fato que a comunicação, hoje, se apresenta com intenso e igual poder de nos unir ou nos isolar.

\section{Referências bibliográficas}

ADORNO, Teodoro; HORKHEIMER, Marx. Dialética do Esclarecimento. Tradução Guido de Almeida, Rio de Janeiro: J. Zahar, 1988

BARTHES, Roland. A cozinha dos sentidos. In: Elementos da semiologia. São Paulo: Cultrix, 1979.

BAUDRILlARD, Jean. Tela Total. Mitos-ironias da Era Virtual e Imagem. Porto Alegre, Sulinas, 2002.

BENJAMIN et al. Textos escolhidos. São Paulo: Abril Cultural, 1980. p. 1-58. (Coleção Os Pensadores).

CASTELLS, Manuel. A sociedade em rede. São Paulo: Paz e Terra, 1999.

CRARY, Jonathan. A visão que se desprende: Manet e o observador atento no fim do século XIX. In: CHARNEY, L.; SCWARTZ, V. (Org.). O cinema e a invenção da vida moderna. São Paulo: Cosac Naify, 2004. cap. 2, p. 67-94.

FERRIN, Isabel. Comunicação e culturas do cotidiano. Lisboa: Quimera,2002. 
JAGUARIBE, Beatriz. O choque do real: estética, mídia e cultura. Rio de Janeiro: Rocco, 2007.

JOHNSON, Steven. A cultura da interface: como o computador transforma nossa maneira de criar e comunicar. Rio de Janeiro: Jorge Zahar, 2001.

HELLER, Agnes. O cotidiano e a história. São Paulo: Paz e Terra, 2008.

LEMOS, André. Cultura da Mobilidade. In: BEIGUELMAN, Giselle \& LA FERLA, Jorge. Nomadismos Tecnológicos. São Paulo, Senac, 2011. . Cibercultura: tecnologia e vida social na cultura contemporânea. Porto Alegre: Sulina, 2002.

LEMOS, André \& LÉVY, Pierre. O futuro da internet: em direção a uma ciberdemocracia planetária. São Paulo, Paulus, 2010.

LEVY, Pierre. O que é o virtual? São Paulo: Editora 34, 1999.

MATTELART, Armanda e Michele. História das teorias da comunicação. São Paulo: Ediçôes Loyola,2004.

MCLUHAN, Marshall. A palavra impressa. In: Os meios de comunicação como extensóes do homem. São Paulo: Cultrix, 1964 p105-205.

MURRAY, Janet. Hamlet on the Holodeck: o futuro da narrativa no ciberespaço. São Paulo: Itaú Cultural, Editora Unesp, 2003.

PEIXOTO, Nelson Brissac. Paisagens urbanas. São Paulo: Senac, 2003.

RAPPAPORT, Erika. Uma nova era de compras: a promoção do prazer feminino no West End londrino, 1909-1914. In: CHARNEY, L.; SCWARTZ, V. (Org.). O cinema e a invenção da vida moderna. São Paulo: Cosac \& Naify, 2004. cap. 5, p. 157-184.

REZENDE, Renata. Tecnologia, Cinema e invenção do corpo contemporâneo: do corpo mecânico ao corpo digital. [Dissertação de Mestrado]. UFF. In: http://www.bdtd.ndc.uff.br/tde_busca/arquivo.php?codArquivo=1576, 2005.

Fragmentos de um corpo: as tecnologias da comunicação e as narrativas na Idade Média e na Idade Mídia [Tese de Doutorado]. UFF, 2009.

SANTOS, Milton. Técnica, Espaço, Tempo. São Paulo: Edusp, 2013.

SENNETT, Richard. Carne e Pedra: o corpo e a cidade na civilização ocidental. Rio de Janeiro: Record, 1997.

SODRÉ, Muniz. Antropológica do Espelho: uma teoria da comunicação linear e em rede. Petrópolis: Vozes, 2002.

WERTHEIM, Margareth. Uma história do espaço: de Dante à Internet. Rio de Janeiro: Jorge Zahar Editor, 2001. 


\section{Notas}

1. Richard Sennett refere-se à obra de William Harvey, De motu cordis, de 1628, na qual suas descobertas sobre a circulação do sangue puseram por terra mais de dois mil anos de uma ciência médica cujos princípios eram "relativos ao calor do corpo que governaram a Atenas de Péricles". A revoluçáo de Harvey mudou a compreensão do corpo de então: "sua estrutura, seu estado de saúde e sua relaçáo com a alma dando origem a uma nova imagem modelo" e teve ressonância nas mais diferentes formas de pensamento, desde Adam Smith, na Riqueza das Naçôes, que reconheceu as contribuiçôes de Harvey para a idéia de um Homo ecomomicus, que "poderia movimentar-se por toda a sociedade, explorar posses e habilidades oferecidas pelo mercado..." a projetos de saúde pública e urbanismo em todo o mundo voltado para "tudo que facilitasse a liberdade do trânsito das pessoas e seu consumo de oxigênio, imaginando uma cidade de artérias e veias contínuas, através das quais os habitantes pudessem se transportar tais quais hemácias e leucócitos no plasma saudável. A revolução médica parecia ter operado a troca de moralidade por saúde e os engenheiros sociais estabelecido a identificação entre saúde e locomoção/circulação. Estava criado um novo arquétipo da felicidade humana”. In SENNETT, Richard. Carne e Pedra: $o$ corpo e a cidade na civilizaçấo ocidental. Rio de Janeiro: Record, 1997.

2. O conceito de noosfera foi elaborado pelo francês Pierre Teilhard de Chardin (18811955) e evoca o compartilhamento de ideias e pensamentos como oportunidade de se alcançar um mundo melhor. Morin (2001) recorre à etimologia do termo noosfera (do grego noos: mente e sphera - corpo limitado por uma superfície redonda) para explicar que o conceito é uma expressáo que representa a camada psíquica nascida da noogênese que cresce e envolve nosso planeta acima da biosfera (camada formada pela multidão de seres vivos, que cobre a superfície do globo). Para Morin, a noosfera é, portanto, o resultado da noogênese: uma camada mais madura, em crescimento e definitiva, estabelecida pelo conjunto do pensamento do ser humano, que está aberta a todas as transformaçôes sutis, desde o estado primitivo até a abrangência de todo o conhecimento humano, às ideias e às tecnologias cada vez mais complexas (2001, p.139). Sodré (2002, p.132) sintetiza o conceito como "um meio-ambiente vinculado a ecossistemas intelectivos ou um ethosauto-organizado e mediador das relaçôes de saber entre os sujeitos e o indivíduo consigo mesmo". 